\title{
Study on the Teaching Mode of Fundamentals of Architectural Design Based on Chinese Culture
}

\author{
Haibeibei YUAN \\ Doctor, Dalian University of Technology, China \\ Associate Professor, Tianjin Chengjian University, China
}

Wei LU

Professor, Dalian University of Technology, China

\begin{abstract}
Through the development of more than half a century, from construction technology to design ideology, Chinese architecture is always lagging behind or in the process of learning, which not only caused the collective confidence missing in national traditional culture but also led to the all same pattern in Chinese architectural internationalization. This article has put forward constructive solutions on establishing the teaching mode integrating the Chinese traditional architectural culture into the architecture foundation courses, from cultural translation, design combined with construction and teaching students in accordance of their aptitude. Through the analysis of the traditional Chinese architectural culture and China's current situation of Architectural Education, the embedded teaching mode of the two aspects' combination is to be advocated. It will help students to get better design integrated with the Chinese traditional humanistic spirit and to implement the regional modern architecture renaissance with Chinese geographical characteristics.
\end{abstract}

KEYWORD: Chinese Culture; Fundamentals of architectural design; teaching mode

The Fundamentals of architectural design is the introductory course of the architecture design. It helps students to step into the professional learning. As the transition of basic education with occupation education, it plays a decisive role for the future of students on their road of life. In this course, the students should not only be taught professional knowledge but also to get stimulated interests on learning and so as to establish the necessary responsibility and occupation moral. Therefore, it is a complex curriculum. Students of today are the architects of the future. The teaching orientation today will influence the future architectural trends of China. In recent years, the construction industry of China is influenced highly by the western architectural thoughts. The trend of the west worship is becoming obvious in the architecture design, construction scheme and sense of worth. The reason to this situation, on the one hand is due to the backwardness of the architectural discipline in China, on the other hand, the blindly advocating native education integrated with foreign standards in the professional teaching and ignorant of the traditional architectural culture essence. Therefore, it is necessary to create a teaching mode integrating the fundamentals of architectural design with Chinese characteristics in architectural enlightenment education.

\section{THE CONTEMPORARY TRANSLATION OF CHINESE CLASSICAL ARCHITECTURAL CULTURE}

"Architecture inevitably is an organic part of the whole cultural system, it is influenced by the other part, but also affect the other part. It is very difficult to imagine the cultural system without architecture."[1] Chinese classical architectural culture is a microcosm of Chinese traditional philosophy. Throughout Chinese history, the dominant position philosophy is mainly Confucian, Taoism and Zen Buddhism thought. Their philosophy advocated deeply reflection in the design concept of Chinese classical architecture. In the western theories of modern architecture, architecture is the crystallization materialized of social cultural activity, and space is the main issue in building design, the properties and characteristics of space reflects the social value of building. Therefore, although the earth-shaking changes have taken place in construction technology, building materials, but the cultural values defined by spatial features in architectural design can have the spatial characteristics of Chinese traditional architecture, and reflects the strong vitality of traditional culture in the new era.

Confucianism is Confucius' political ideal to seek order in the Warring States period. Although there 
are many fealty dross, but its attempts to establish the general rule of the world and the thought of looking for stable order deeply influenced the feudal society construction system, such as the city planning, roofs shapes, spatial order etc. which reflected in a strict rank and order, and these are perfectly in harmony agreement with the primary and secondary idea, the whole and global concept and the logic rules controlled by the Euclidean geometry in western architectural theory. Taoism advocates "Man models himself after Earth, Earth models itself after Heaven, Heaven models itself after Tao, and Tao models itself after its Nature", the pursuit of a harmony realm of nature and man has a profound impact on the core value of Chinese ancient nobility. Therefore, in the culture of architecture it also reflects advocating natural, hermitage forest and subtle, simple aesthetic taste etc. Chinese classical garden is the representative of this thought. Zen promotes the pursuit of artistic conception beauty of Chinese ancient architectural environment, and began to pay attention to the symbiotic relationship between people's spiritual world and building environment. The intelligentsia had made themselves more clear of the ideal living environment by the thought of living poetic. In summary, the philosophy does influence the Chinese classical architectural culture and make the character of Chinese classical architecture with distinctive features. The reserved, introverted, derived from nature but higher than that of nature and undemonstrative spatial processing technique is the materialized results from classical culture on Architecture. While teaching the fundamentals of architectural design, a teacher should realize that how to successfully realize the translation of Chinese classical architectural culture is an important segment to ensure the inheritance and development of traditional culture. You can start from the following aspects:

1. Strengthen the understanding and memory of classical architecture paradigm, such as the roof forms, ornamental perforated window styles, paving patterns and so on, by copy drawing, collage, model and other means.

2. Select description chapters on architectural environment of classical literature, students begin to recreate the new composition design according to their conception and imagination. It helps to restore the essence space tableaux in those works (such as the description of the landscape in the Grand View Garden in a dream of Red Mansions).

3. On-the-spot investigation and surveying can help students to experience the atmosphere of the space in real scenes.

4. Based on the classic western architecture theory, by analysis and dismantling the elements of Chinese classical architectural cases, such as the path, vision, space order, space proportion, light and shadows, color, construction and so on, students get to understand in-depth the key factors of Chinese classical architecture. And then some day, they will create some fabulous architecture spaces with great Chinese traditional culture temperament, though they still make use of modern materials for construction.

\section{COMBINED THE CONSTRUCTION WITH DESIGN ON THE TEACHING MODE}

Status and significance of architecture are obviously different in Chinese and western culture. Chinese ancient building is a symbol of the regime of ruling class. The techniques of construction art got inheritance by mentoring the continuation of the builders. Only the architecture and landscape design and layout for the royal or official family is accomplished by scholars who understands geomancy well. It determines the craftsmen have high degree of freedom on technical problems of overall grasp in this kind of building construction process, such as structural stability, structure, construction procedure etc. At the same time, because the timber work plays a dominant role in Chinese ancient architecture, the carpenter's skill plays a key role on the building's success. So, the Chinese architectural culture of thousands of years is a wood construction history indeed. Chinese traditional construction craftsmen created mature wood construction mode, which could be a profound reference for the current architectural design. Although in modern buildings, steel and concrete become mainstream building materials, but with the development of technology, synthetic wood also has a huge development potential. The relevant experiments testify that the performance of wood shows their own advantages and characteristics in the fire. The shear capacity of the steel is reduced to zero at once just after melting point as in arrived. But the shear capacity and the strength of wood will gradually reduce and maintain stable for a longer period of time after the initial fire surface carbonization. Therefore, the development and utilization of timber construction and other natural materials remains a puzzle which need to be solved by further research. Because of the light quality and easy operation of wood, it is an ideal material in construction courses. Currently Many architecture schools and universities are equipped with woodworking machine suits, students can design and product structure node model with scale of 1:1 under the guidance of teachers, so as to obtain the opportunities to understand and practice the construction knowledge.

It is fine tradition for the modern architecture education to begin with the construction practice. 
Since the Bauhaus age, the students took operation personally in the workshop and built model design and production to deepen understanding. Brackets are the core component in Chinese wooden building science. As visual elements of symbolic significance it solved the structure force conduction. Research on China architectural culture should get start from the learning on brackets, students should be encouraged to make physical brackets model by themselves. The utility of other natural materials will enhance students' understanding of the nature of the construction. In recent years, the research on how to make use of bamboo in some colleges in the South has made certain achievements. Fast growth, good toughness, easy to access, the bamboo is taking a good prospect of application development in the construction of disaster prevention. It can always arouse students the enthusiasm of design to construct a micro architectural space as a real case by using the traditional building materials. It helps to deepen their understanding of the knowledge about scale, modulus, construction and space at the same time.

Module system generation is the key issue on construction system, the monomer form and detail design will affect the whole stability, functional use and artistic style of the building. Under the background of modern industrial production, the module manufacturing will build the basement of architectural design. Therefore, it will guide the future of Chinese architecture towards the regional characteristic development road to combine with the design of construction and make good advantage of the traditional architectural technology.

\section{TEACHING STUDENTS IN ACCORDANCE WITH THEIR APTITUDE}

Affected by the examination oriented education mechanism, Chinese first grade students of architecture are not comparable in the professional cognition, basis of art and artistic accomplishment with the first grade students of developed countries, which seriously delayed the students' pace walking into the professional learning area. The architecture is a practical art, it is the embodiment of cultural achievement of a certain historical period, a set of practical and aesthetic. It has the characteristics of both art and technology. Without artistic nourishment, it is difficult to stimulate an architect to accomplish the outstanding architectural design works with creative and spiritual shock. In the foreign education system, the students began to choose majors according to inner passion and interest in their high school. Before they start their professional university learning, they have understood the projects to a deep level. And It's difficult for the Chinese students to match them on cultivation of art, aesthetic taste preferences and so on. Therefore, they have to spend lot of time on the literacy learning of art. It is the primary problem of this course about how to help students as soon as possible to enter the architecture professional learning state. The key is to teach students in accordance with their aptitude and help them to change their thinking mode of learning soon.

Compared with the high school learning, great changes have taken place in the characteristics of the subject, the corresponding learning style and the evaluating method on the learning results of the performance will also change. Students should realize that the mathematics is no longer your major as in high school and the main training contents will be painting, handmade, computer graphics and these spare time hobbies will become the basis of design and should be paid great attention; Scores will no longer be the only evaluation standard of academic achievement, the process and experience will be the professional learning chips increasingly accumulated; Solutions to specific problems will have no standard answer, there is no best but better will be the starting point and goal of the work in the future; In order to help students to get progress through this transition period, we should take cultivating the following ability as the main target when we make syllabus design, set up the subject and plan the operation mode in the courses of fundamentals of architectural design.

1. Independent study ability. Chinese high school students are accustomed to the way of learning as listening + tests, which limits the students' subjective initiative to a certain extent, while passive learning is a big shortage in university professional learning. The professional knowledge of architecture covers a wide range. It is difficult for a student to solve many problems facing in the future as architects by only spend hours learning in the classroom. He will barely achieve the basic requirements of architects education without active access to information in his afterschool time and improve their own knowledge structure. Therefore, we should actively lead them to the right way when we design the syllabus and set up the operating projects. Such as enhancing the interest of design topics and practicability, merging the technique training into the design of the subject, stimulating students interest in learning and creating a bibliography; We should provide detailed task book, increase the knowledge dabbling category, encourage students to set up questions by themselves, communication, and take good positive thinking and solving problem based on the extracurricular reading.

2. The ability to express. Ability to express help students to make his design intent clear, namely that their own design concept and be able to help 
others to understand their own design work. It is the basic quality for a successful designer. Currently the involved techniques include architectural painting, modelling, analysis chart, CAD and oral speech. Excellent expression ability is helpful for designers to sell his own products and to persuade others to accept their design philosophy. Cultivation of this ability will run through the entire architecture professional learning, which is lack in the Chinese basic education. In the architectural design fundamentals course, the students should understand the importance and necessity of expression ability training, and actively follow the teaching process. For examples, put stage reports into the curriculum design process, and create opportunities for students to practice their ability of oral expression; as to other expression abilities the teacher should encourage students to choose 2-3 strengthening exercises according to their own characteristics and interests .

3. Team work. Team work is the key to success in the future society. As an architect, he should possess coordination ability, which requests the student to get used to benefit by mutual discussion, cooperation and coordinate development of the working habits in the learning stage, set up the team consciousness, enhance the sense of collective honor. A teacher should appropriately increase the workload and promote group cooperative ; establish the display platform for sharing, urge the students to strengthen the understanding of individual design with flocks of organizational relationship. For example, in the spatial light-shadow design topic, each student will design a single model in volume and basal area within the set scale, and then a large site model will be produced, which provides a certain arrangement order for each student's works. The works are going to be inserted into the shared site model. From this exercise, the students will get deeper understanding from the combination of different forms of individual and overall awareness and establish the sense of team cooperation.

It is a long process for Chinese architecture to walk out of its own cultural features revival road, but it has become an unstoppable torrent. Decades have passed since Liang Sicheng proposed this problem for the first time and this problem will be solved in the near future under the guidance of the Modern Architectural Education, Chinese architects will gradually get clearly thinking clue to achieve the great cross- century goal.

\section{REFERENCE}

[1] Wang Lumin, "The origin of Chinese classical architecture cultural" Tongji University press 1997, Taiwan King enterprises Limited by Share Ltd 1999. 